\title{
Low-temperature-induced adaptations in fatty acid metabolism of Acanthamoeba castellanii cultures of different ages: relationship to changes in cell division, oxygen uptake and phagocytotic activity
}

\author{
Simon V. Avery, ${ }^{1}$ John L. Harwood ${ }^{2}$ and David Lloyd ${ }^{1}$ \\ Author for correspondence: Simon V. Avery. Tel: +44222874000 ext. 5884/6810. Fax : +44222874305.
}

Microbiology Group, School of Pure and Applied

Biology', and Department of Biochemistry², University of Wales College of Cardiff, PO Box 915, Cardiff CF1 3TL, UK
The degree of unsaturation of membrane lipids of Acanthamoeba castellanii at $30{ }^{\circ} \mathrm{C}$ decreased with batch-culture age. These changes were primarily attributable to a decline in microsomal $\Delta 12$-desaturase activity and in the relative proportion of linoleate. No change in the fatty acid composition, $\Delta 12$-desaturase activity or any increased incorporation of $\left[1-{ }^{14} \mathrm{C}\right]$ acetate into polyunsaturated fatty acids was observed following chilling of early- and midexponential-phase cultures to $15^{\circ} \mathrm{C}$. In contrast, chilling of late-exponential and stationary-phase cultures resulted in a rapid and marked increase in the synthesis of polyunsaturated fatty acids. Thus, after $12 \mathrm{~h}$ incubation at $15^{\circ} \mathrm{C}$, the relative proportions of oleate and linoleate in these older cultures were similar to those of early- and mid-exponential-phase cultures at $30^{\circ} \mathrm{C}$. Despite these differences, an approximately $9.5 \mathrm{~h}$ lag in cell division was evident following chilling of both mid-exponential and late-exponential/earlystationary-phase cultures, and the subsequent pattern of cell division over $60 \mathrm{~h}$ incubation was similar in both cases. Oxygen uptake rates in cultures of either age were also decreased approximately equally at $15^{\circ} \mathrm{C}$. In contrast, chilling of mid-exponential-phase cells resulted in only an approximately $44 \%$ reduction in the rate of phagocytosis of fluorescently-labelled latex beads, whereas an approximately $98 \%$ inhibition of phagocytosis by late-exponential/earlystationary-phase cells resulted at $15{ }^{\circ} \mathrm{C}$. Furthermore, a gradual subsequent increase in the rate of phagocytosis at $15^{\circ} \mathrm{C}$ was only observed in the older cultures and was correlated with increases in the fatty acid unsaturation index of these cells. Thus, $12 \mathrm{~h}$ after chilling, the cells from late-exponential/earlystationary-phase cultures had achieved rates of phagocytosis similar to those of chilled cells from mid-exponential growth and their fatty acid compositions were now similar. The results suggest a role of membrane lipid unsaturation in the control of phagocytotic activity of $A$. castellanii.

Keywords: Acanthamoeba castellanii, low temperature adaptation, fatty acid unsaturation, $\Delta 12$-desaturase, phagocytosis

\section{INTRODUCTION}

The soil amoeba Acanthamoeba castellanii is subject to marked spatial and temporal changes in temperature in its natural habitat. The requirement for rapid physiological adaptation of this poikilothermic organism to sudden chilling is apparently facilitated by temperature-compensation of certain cellular functions. For example, the periodicities of ultradian rhythms in $A$. castellanii remain almost constant over a temperature range $\left(20-30^{\circ} \mathrm{C}\right)$ which is associated with marked changes in the cell doubling time (Lloyd et al., 1982; Lloyd \& Edwards, 1987). Furthermore, recent studies on changes in lipid metabolism following a temperature shift-down have suggested a role of temperature compensation of membrane fluidity during low-temperature adaptation in $A$. 
castellanii (Jones et al., 1991, 1993a). Homeoviscous adaptation, the maintenance of a particular physical state of membranes, has been described in many diverse organisms in response to chilling and is implicated as being a prerequisite for the maintenance of certain cellular processes at low temperature, e.g. the activities of membrane-associated enzymes and transport proteins (Hazel \& Williams, 1990). However, despite the extensive literature detailing the biochemistry of temperatureinduced changes in lipid metabolism, surprisingly few studies have sought to establish a relationship between these adaptations and changes in physiological function.

In $A$. castellanii, a very rapid change in lipid metabolism, characterized by increases in the proportions of $18-\mathrm{C}$ and also $20-C$ polyunsaturated fatty acids, is evident within $10 \mathrm{~min}$ of chilling late-exponential-phase cultures from $30{ }^{\circ} \mathrm{C}$ to $15^{\circ} \mathrm{C}$ (Jones et al., 1991, 1993a). These adaptations have been attributed primarily to the induction of the microsomal $\Delta 12$-desaturase, which catalyses the conversion of oleate to linoleate on complex lipid substrates (Jones et al., 1993a). It has been observed that an approximate $10 \mathrm{~h}$ lag in cell division, following temperature shift-down in $A$. castellanii, corresponds to the time required for the completion of membrane-lipid modifications and it was suggested that these alterations may be needed for the resumption of cell division at the lower temperature (Jones et al., 1991).

Recent studies with $A$. castellanii have revealed that increases in lipid unsaturation similar to those observed during chilling of the organism occur after inoculation of late-exponential-phase cells into fresh medium at $30^{\circ} \mathrm{C}$ (Avery et al., 1994). In this case, large increases in the proportions of polyunsaturated fatty acids during earlyexponential growth in batch culture, followed by decreases in lipid unsaturation during late-exponential growth, are entirely independent of temperature. Thus, two separate parameters elicit similar responses in the lipid metabolism of $A$. castellanii, suggesting that the organism may serve as a useful model for distinguishing those adaptations that are a direct response to temperature shift-down, from those that constitute a more general cellular response to environmental changes.

The purpose of the present study was to determine whether differences in the degree of lipid unsaturation at different stages of growth influence low-temperatureinduced adaptations of membrane lipids and physiological function in $A$. castellanii. Measurements of fatty acid composition, $\left[1-{ }^{14} \mathrm{C}\right]$ acetate incorporation and $\Delta 12$-desaturase activity were used to determine the effect of chilling on lipid metabolism in cultures of different ages. Further experiments sought to relate these observations to physiological activity, determined through measurements of cell division, whole cell oxygen uptake and phagocytosis, both before and after chilling of mid- and late-exponential-phase cultures. The major conclusions are that unlike rates of oxygen uptake and cell division, phagocytotic activity is markedly influenced by the degree of fatty acid unsaturation.

\section{METHODS}

Organism and culture conditions. Acanthamoeba castellanii was grown in PGY medium, containing $(\%, \mathrm{w} / \mathrm{v})$ : Difco proteose peptone, $0 \cdot 75$; Oxoid yeast extract, $0 \cdot 75$; glucose, $1 \cdot 5$. Cultures $(200 \mathrm{ml}$ in $500 \mathrm{ml}$ Erlenmeyer flasks) were inoculated with 48-hold organisms, to give an initial cell density of approximately $2 \times 10^{5} \mathrm{ml}^{-1}$, and were incubated at $30^{\circ} \mathrm{C}$ with rotary aeration at 200 r.p.m. For temperature-shift experiments, flasks were placed in an ice slurry and cultures were agitated using a magnetic stirrer. After approximately $4.5 \mathrm{~min}$, when the temperature of the cultures had decreased to approximately $15^{\circ} \mathrm{C}$, the flasks were transferred to a shaking incubator $(200$ r.p.m.) and incubated at $15^{\circ} \mathrm{C}$. Samples for lipid analysis were harvested by centrifugation for $1 \mathrm{~min}$ at $750 \mathrm{~g}$. To examine the influence of chilling on cell division, cells from cultures of the appropriate age were inoculated (to approximately $2 \times 10^{5} \mathrm{cells} \mathrm{m}^{-1}$ ) into fresh medium at $15{ }^{\circ} \mathrm{C}$ and incubated as described above.

Cell numbers were determined using a Fuchs-Rosenthal haemocytometer slide, after appropriate dilution with distilled water: more than 1200 cells were counted in each sample. Dry weights were determined using pre-weighed tared foil cups, dried to a constant weight at approximately $100^{\circ} \mathrm{C}$.

[1- ${ }^{14} \mathrm{C}$ ]Acetate incorporation and $\Delta 12$-desaturase assay. For acetate labelling studies, approximately $1.5 \mathrm{MBq}\left[1-{ }^{14} \mathrm{C}\right]$ acetate was added directly to $200 \mathrm{ml}$ culture of the appropriate age. Cells $(5 \mathrm{ml})$ were harvested at the specified intervals.

Microsomal $\Delta 12$-desaturase activity was determined by measurement of the conversion of oleate to linoleate in isolated microsomal membranes, using $\left[1-{ }^{14} \mathrm{C}\right]$ oleoyl $\mathrm{Co} A$ as a radiolabelled precursor, as described previously (Jones et al., 1993a).

Lipid analyses. Lipids were extracted using the method of Bligh \& Dyer (1959) as modified by Griffiths \& Harwood (1991). For fatty acid analysis, methyl esters were generated by acidcatalysed methanolysis $\left[2.5 \%(\mathrm{v} / \mathrm{v}) \mathrm{H}_{2} \mathrm{SO}_{4}\right.$ in methanol $]$ at $70^{\circ} \mathrm{C}$ for $2 \mathrm{~h}$. After extraction with light petroleum (b.p. $60-80^{\circ} \mathrm{C}$ ), aliquots of methyl esters were analysed by radiogas-liquid chromatography. Heptadecanoate was used as an internal standard. Separations were routinely achieved using $10 \%$ SP-2330 on 100/120 Supelcoport (Supelco) packed into a glass column $[1.5 \mathrm{~m} \times 4 \mathrm{~mm}$ (i.d.)]. Fatty acids were identified by comparison with authentic standards and had been fully identified previously (Jones et al., 1991). Fatty acids were quantified using the method of Carroll (1961) or by using integrating software (Lab Logic).

Radioactive counting. Radioactivity in separated fatty acids was estimated in a gas-flow proportional counter (Lab Logic) after catalytic conversion to ${ }^{14} \mathrm{CO}_{2}$. For total counts, samples in Optifluor (Packard) were analysed using a LKB 1209 Rackbeta liquid scintillation counter. The counts were corrected for background and for quenching using an external standard ratio method.

Measurement of oxygen uptake. Oxygen uptake rates by $A$. castellanii cultures were measured both prior to and at appropriate intervals after chilling, using a Rank oxygen electrode linked to a Kipp and Zonen potentiometric recorder. Rates were determined when constant at either $30^{\circ} \mathrm{C}$ or $15^{\circ} \mathrm{C}$. The chamber volume used was $3 \mathrm{ml}$ and calibration was by means of airsaturated distilled water; oxygen solubility values at both assay temperatures (237 and $315 \mu \mathrm{M} \mathrm{O}_{2}$ at $30^{\circ} \mathrm{C}$ and $15^{\circ} \mathrm{C}$, respectively) were obtained from Golterman (1969).

Phagocytosis assay. Undiluted culture samples $(0.9 \mathrm{ml})$ were transferred to $1.5 \mathrm{ml}$ microcentrifuge tubes and incubated with shaking (200 r.p.m.) at $30^{\circ} \mathrm{C}$ or $15^{\circ} \mathrm{C}$, in either the absence or 
presence of $12.5 \mathrm{mM}$ sodium azide. After 5 min equilibration, $100 \mu \mathrm{l}$ fluorescently labelled yellow-green latex microbeads ( $1.0 \mu \mathrm{m}$ diam.; Polysciences) were added to the tubes to a final concentration of approximately $5 \times 10^{7}$ beads $\mathrm{ml}^{-1}$. After 15 min incubation with latex beads, phagocytosis was stopped by dilution of the cell plus bead suspension to $10 \mathrm{ml}$ with buffer (100 mM mannitol, $15 \mathrm{mM} \mathrm{NaH} \mathrm{PO}_{4} \cdot 2 \mathrm{H}_{2} \mathrm{O}, \mathrm{pH} 7 \cdot 2$ adjusted using $2 \mathrm{M} \mathrm{NaOH}$ ) at $4{ }^{\circ} \mathrm{C}$. Cells were separated from free beads by centrifugation for $1 \mathrm{~min}$ at $750 \mathrm{~g}$, and the bead-containing supernatant was discarded. The cell pellet was resuspended in $1 \mathrm{ml}$ buffer and maintained at $4{ }^{\circ} \mathrm{C}$ until analysis. All samples were analysed within $24 \mathrm{~h}$; control experiments confirmed that no loss of beads from cells occurred during storage at $4{ }^{\circ} \mathrm{C}$ for up to 1 week.

Cells were analysed for fluorescent beads using a flow cytometric method adapted from Steinkamp et al. (1982). Sample analysis was performed using a Skatron Argus flow cytometer. Photomultiplicr voltages were 200 and $375 \mathrm{~V}$, and gain settings were $1 \cdot 0$ and $4 \cdot 0$, for forward-angle light scatter and fluorescence, respectively. Green fluorescence signals were collected using an Argus FITC filter block. Fluorescence histograms were gated by forward-angle light scatter so that only data for cellassociated fluorescence were presented; noise and fluorescence from residual free beads that had not been taken up by the cells were not recorded. A typical histogram contained data from approximately 30000 cells, measured at a flow rate of 5-10 $\mu \mathrm{l}$ $\min ^{-1}$. The proportion of cells that had taken up fluorescent beads, as well as numbers of cells under each peak of fluorescence (the intensity of fluorescence of each peak being linearl related to the number of beads taken up), were obtained by appropriate adjustment of cursors on the fluorescence histogram. The latter value allowed calculation of the total number of beads taken up by a sample of cells. The mean number of beads bound to the cell surface was obtained from fluorescence histograms of cells incubated in the presence of sodium azide. These values were subtracted from those obtained for cells incubated in the absence of sodium azide, to give the mean number of phagocytosed beads.

\section{RESULTS}

\section{Effect of chilling on fatty acid composition in A. castellanii cultures of different ages}

Marked changes in the degree of lipid unsaturation of $A$. castellanii occurred during batch growth at $30^{\circ} \mathrm{C}$. These grow th-stage dependent changes were most evident in the relative proportions of oleate and linoleate, and for clarity only these data are presented in Fig. 1. In early- $(12 \mathrm{~h})$ and mid- $\left(24 \mathrm{~h}\right.$ ) exponential-phase cultures at $30^{\circ} \mathrm{C}$ (corresponding to $0 \mathrm{~h}$ in Fig. 1) the polyunsaturated fatty acid linoleate accounted for approximately $21 \%$ of total cellular fatty acids, whereas the monounsaturated oleate accounted for only approximately $13-16 \%$ of total fatty acids (Fig. 1a, b). After $24 \mathrm{~h}$ the relative proportion of oleate increased, while that of linoleate decreased, and in stationary-phase cultures $(48-72 \mathrm{~h})$ at $30{ }^{\circ} \mathrm{C}$ these fatty acids accounted for approximately 44 and $8 \%$ of total cellular fatty acids, respectively (Fig. 1d-f).

Changes in the fatty acid composition of $A$. castellanii were examined over a $12 \mathrm{~h}$ time course, following chilling of cultures at various stages of growth to $15^{\circ} \mathrm{C}$. As with growth at constant temperature, changes in fatty acid unsaturation after chilling were most marked and rapid in the relative proportions of oleate and linoleate. In 12 and $24 \mathrm{~h}$ cultures, chilling had negligible effect on the degree of fatty acid unsaturation and the relative proportions of oleate and linoleate remained approximately constant at the lower temperature (Fig. 1a, b). In contrast, the level of oleate decreased by approximately $5 \%$ as a proportion of total cellular fatty acids, while that of linoleate increased by approximately $7 \%$, in the $12 \mathrm{~h}$ after chilling of cells in the late-exponential growth phase $(36 \mathrm{~h})$. After $12 \mathrm{~h}$, the proportions of oleate and linoleate in these cells (Fig. 1c) were similar to those observed in 12 and $24 \mathrm{~h}$ cultures both before and after chilling (Fig. 1a, b). Temperaturedependent changes in fatty acid composition were most marked in stationary-phase cultures, where the degree of fatty acid unsaturation at $30^{\circ} \mathrm{C}$ was lowest. In the $12 \mathrm{~h}$ period after chilling, oleate in 48,60 and $72 \mathrm{~h}$ cultures decreased from approximately $44 \%$ to about $20 \%$ as a proportion of total cellular fatty acids, while linoleate increased from approximately $8 \%$ to about 30\% (Fig. $1 d-f)$. The final levels of oleate, and particularly linoleate, $12 \mathrm{~h}$ after chilling of stationary-phase cultures were higher than those observed in early- and mid-exponential cultures.

\section{Effect of chilling on labelling of individual fatty acids from $\left[1-{ }^{14} \mathrm{C}\right]$ acetate in $A$. castellanii cultures of different ages}

The de novo synthesis of fatty acids was examined in unchilled and chilled $A$. castellanii cultures at various stages of growth using $\left[1-{ }^{14} \mathrm{C}\right]$ acetate as a precursor. Rates of total $\left[1-{ }^{14} \mathrm{C}\right]$ acetate incorporation were approximately linear over the $2 \mathrm{~h}$ time course examined. However,

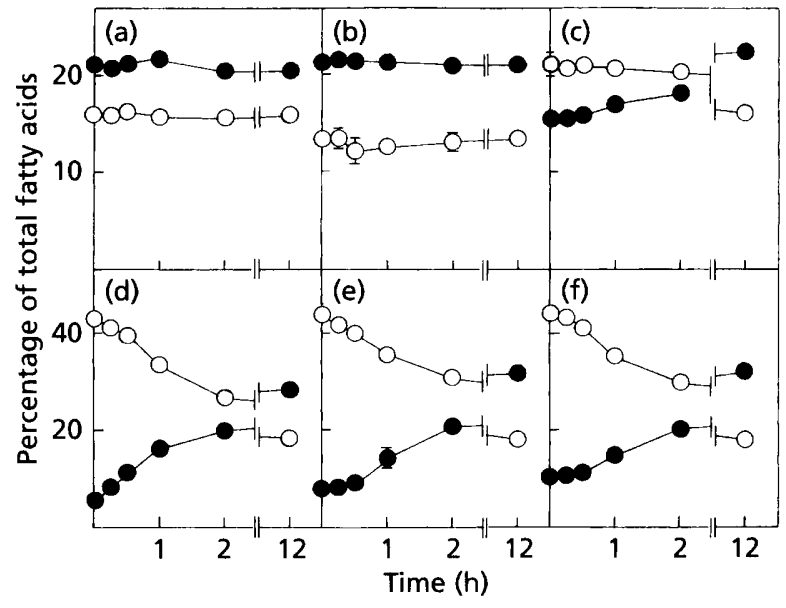

Fig. 1. Effect of chilling on oleate and linoleate composition of A. castellanii cultures of different ages. Cells were grown in

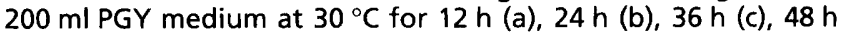
(d), $60 \mathrm{~h}(\mathrm{e})$ and $72 \mathrm{~h}(\mathrm{f})$. Cultures were then chilled to $15^{\circ} \mathrm{C}$ and the fatty acid composition monitored over the subsequent $12 \mathrm{~h}$ incubation at $15^{\circ} \mathrm{C}$. The graph shows percentage values for oleate $(O)$ and linoleate $(0)$ as proportions of total cellular fatty acids. Mean values are shown from three replicate determinations \pm SEM where these exceed the dimensions of the symbols. 
Table 1. Effect of chilling on labelling of unsaturated fatty acids from $\left[1-{ }^{14} \mathrm{C}\right]$ acetate in $\mathrm{A}$. castellanii cultures of different ages

Approximately $1.5 \mathrm{MBq}\left[1-{ }^{14} \mathrm{C}\right]$ acetate was added directly to cultures of the appropriate age either at $30{ }^{\circ} \mathrm{C}$ or immediately after chilling to $15^{\circ} \mathrm{C}$. Fatty acids are abbreviated with the first figure showing the number of carbon atoms and the second indicating the number of double bonds. Values shown are percentages of total incorporated radiolabel, determined after $2 \mathrm{~h}$ incubation of cells with $\left[1-{ }^{14} \mathrm{C}\right] \mathrm{acetate}$, and are means from three replicate determinations \pm SEM $(\operatorname{tr}$, SEM $<0 \cdot 1)$.

\begin{tabular}{|c|c|c|c|c|c|c|c|c|c|c|c|c|}
\hline \multirow[t]{2}{*}{ Age of culture... } & \multicolumn{2}{|c|}{$12 \mathrm{~h}$} & \multicolumn{2}{|c|}{$24 \mathrm{~h}$} & \multicolumn{2}{|c|}{$36 \mathrm{~h}$} & \multicolumn{2}{|c|}{$48 h$} & \multicolumn{2}{|c|}{$60 \mathrm{~h}$} & \multicolumn{2}{|c|}{$72 \mathrm{~h}$} \\
\hline & $30{ }^{\circ} \mathrm{C}$ & $15^{\circ} \mathrm{C}$ & $30{ }^{\circ} \mathrm{C}$ & $15^{\circ} \mathrm{C}$ & $30^{\circ} \mathrm{C}$ & $15^{\circ} \mathrm{C}$ & $30^{\circ} \mathrm{C}$ & $15^{\circ} \mathrm{C}$ & $30^{\circ} \mathrm{C}$ & $15^{\circ} \mathrm{C}$ & $30^{\circ} \mathrm{C}$ & $15^{\circ} \mathrm{C}$ \\
\hline ()icate $18: 1(n-9)$ & $21 \cdot 4 \pm 0.9$ & $24 \cdot 8 \pm 0 \cdot 6$ & $19 \cdot 8 \pm 0 \cdot 7$ & $26 \cdot 2 \pm 0.8$ & $49 \cdot 7 \pm 0 \cdot 9$ & $37 \cdot 4 \pm 0 \cdot 6$ & $41 \cdot 9 \pm 0 \cdot 2$ & $37 \cdot 1 \pm 1 \cdot 1$ & $32 \cdot 0 \pm 2 \cdot 3$ & $29 \cdot 5 \pm 1 \cdot 0$ & $41 \cdot 0 \pm 0.7$ & $29 \cdot 8 \pm 1 \cdot 8$ \\
\hline Lincleate $18: 2(n-6)$ & $20 \cdot 4 \pm 0 \cdot 7$ & $11 \cdot 1 \pm 0 \cdot 3$ & $16 \cdot 4 \pm 0 \cdot 3$ & $11 \cdot 0 \pm 1 \cdot 2$ & $5 \cdot 4 \pm 0 \cdot 8$ & $9 \cdot 0 \pm 0 \cdot 2$ & $1 \cdot 0 \pm 0 \cdot 5$ & $10 \cdot 7 \pm 1 \cdot 2$ & $1 \cdot 6 \pm 0 \cdot 1$ & $17 \cdot 9 \pm \operatorname{tr}$ & $0.5 \pm 0 \cdot 3$ & $16.7 \pm 0 \cdot 1$ \\
\hline [iicosadiencatc 20:2(n-6) & $6 \cdot 1 \pm 0.3$ & $4 \cdot 8 \pm 0 \cdot 6$ & $6.5 \pm 1 \cdot 0$ & $5 \cdot 1 \pm 1 \cdot 7$ & $2 \cdot 4 \pm 0 \cdot 2$ & $2 \cdot 8 \pm 0.8$ & $1 \cdot 8 \pm \mathrm{tr}$ & $3 \cdot 9 \pm 0 \cdot 9$ & $2 \cdot 2 \pm 0 \cdot 4$ & $2 \cdot 4 \pm 0 \cdot 1$ & $0.8 \pm 0.1$ & $2 \cdot 1 \pm(3 \cdot 4$ \\
\hline
\end{tabular}

incorporation of radioactivity into individual fatty acids was not linear in all cases, e.g. oleate and linoleate displayed a precursor-product relationship with initial labelling of oleate followed by linoleate, as described previously (Avery et al., 1994). The overall rate of desaturation in total lipids of $A$. castellanii is approximately equal for endogenous oleate and newlysynthesized/incorporated oleate (Jones et al., 1993a). The major unsaturated fatty acids labelled in the $2 \mathrm{~h}$ following addition of $\left[1-{ }^{14} \mathrm{C}\right]$ acetate were oleate, linoleate and eicosadienoate, and these data are presented in Table 1. Saturated fatty acids labelled during this period were myristate, palmitate and stearate. Of the unsaturated fatty acids, most $\left[1-{ }^{14} \mathrm{C}\right]$ acetate was incorporated into oleate. Labelling of oleate at $30^{\circ} \mathrm{C}$ increased markedly in cultures older than $24 \mathrm{~h}$. However, whereas chilling of 12 and $24 \mathrm{~h}$ cultures resulted in approximate $3.4 \%$ and $6.4 \%$ increases in labelling of oleate as a proportion of total labelled fatty acids, respectively, the relative labelling of oleate was decreased following chilling of 36-72 h cultures (Table 1). The effect of culture age and chilling on radiolabelling of linoleate showed the opposite trend to that of oleate. The proportion of $\left[1-{ }^{14} \mathrm{C}\right]$ acetate incorporated into linoleate at $30{ }^{\circ} \mathrm{C}$ decreased approximately 40 -fold with ageing of cultures from 12-72 h, with the most marked transition in the degree of labelling occurring between 24 and $36 \mathrm{~h}$. Conversely, at $15{ }^{\circ} \mathrm{C}$ labelling of linoleate was generally highest in stationary-phase cultures; chilling resulted in a decline in the labelling of linoleate in early-and midexponential-phase cultures, whereas incorporation of radioactivity into linoleate was increased between $1 \cdot 7$-fold $(36 \mathrm{~h})$ and 33 -fold $(72 \mathrm{~h})$ following chilling of older cultures. The decline in linoleate labelling in chilled exponential-phase cultures probably reflects a lower overall rate of cellular metabolism at $15{ }^{\circ} \mathrm{C}$, and accentuates the stimulatory effect of chilling on linoleate synthesis in older cultures. The proportion of [1${ }^{14} \mathrm{C}$ acetate incorporated into the $20-\mathrm{C}$ polyunsaturated fatty acid eicosadienoate was lower than that of oleate and linoleate, but showed similar trends to linoleate, i.e. labelling of eicosadienoate decreased following chilling of 12 and 24 h cultures, but increased following chilling of late-exponential- and stationary-phase cultures of $A$. castellanii (Table 1). Since linoleate is a precursor of this $(n-$ 6) fatty acid, such a result was to be expected.

\section{Effect of chilling on microsomal $\Delta 12$-desaturase activity in $A$. castellanii cultures of different ages}

As the most marked growth- and temperature-dependent changes in lipid unsaturation of $A$. castellanii were evident in the relative levels and synthesis of oleate and linoleate, the influence of chilling on microsomal $\Delta 12$-desaturase activity, which catalyses the desaturation of oleate to linoleate in A. castellanii (Jones et al., 1993a) was examined in cultures at different stages of growth. Desaturase activity was examined both before and $1 \mathrm{~h}$ after chilling of cultures from $30^{\circ} \mathrm{C}$ to $15^{\circ} \mathrm{C}$. The protein content of microsomal membranes as a proportion of membrane dry weight was found to vary significantly with culture age and temperature. Thus, in order to eliminate any variability in calculated enzyme activities attributable to changes in the protein:lipid ratio, desaturase activity is expressed as [mg (dry wt) membrane $]^{-1}$. The values for desaturase activity, determined under optimal assay conditions in vitro, actually underestimate the true activity because the desaturation of endogenous substrate occurs simultaneously and accounts for over $90 \%$ of the total desaturation (Jones et al., 1993a). $\Delta 12$-Desaturase activity was maximal in early- and mid-exponential-phase cultures at $30^{\circ} \mathrm{C}$, at around $1200 \mathrm{pmol}(\mathrm{mg} \text { membrane })^{-1} \mathrm{~h}^{-1}$, but declined by approximately $50 \%$ between 24 and $36 \mathrm{~h}$ growth (Fig. 2). Induction of $\Delta 12$-desaturase activity was evident when late-exponential- and stationary-phase cultures were chilled to $15^{\circ} \mathrm{C}$. Chilling of $36 \mathrm{~h}$ cultures resulted in an approximate $60 \%$ increase in measured $\Delta 12$-desaturase activity, while maximal induction was evident in $60 \mathrm{~h}$ cultures where desaturase activity in isolated microsomal membranes from chilled cultures was approximately $145 \%$ higher than in those from cultures maintained at $30^{\circ} \mathrm{C}$ (Fig. 2). In contrast, no induction of desaturase activity was evident after chilling of 12 and $24 \mathrm{~h}$ cultures, and measured rates of oleate desaturation were maintained at relatively high levels in these cases.

\section{Influence of chilling on cell division in 24 and $\mathbf{4 8 ~ h}$ cultures of $\boldsymbol{A}$. castellanii}

The effect of chilling on cell division in cultures of different ages was examined to determine whether differences in the degree of lipid unsaturation at $30^{\circ} \mathrm{C}$, and in the subsequent lipid modifications at $15^{\circ} \mathrm{C}$, influenced the 


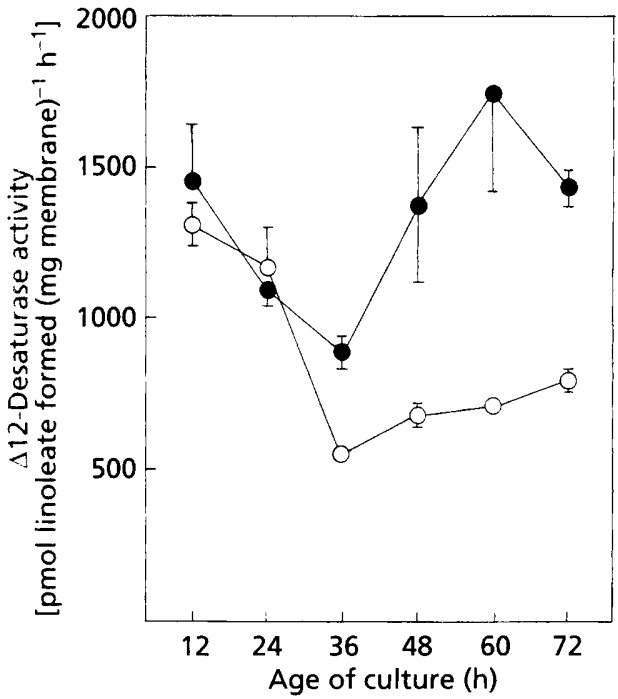

Fig. 2. Effect of chilling on microsomal $\Delta 12$-desaturase activity in $A$. castellanii cultures of different ages. Microsomal membranes were isolated from cells at various stages of growth in PGY medium at $30^{\circ} \mathrm{C}$, both prior to $(O)$ and after $(0)$ chilling for $1 \mathrm{~h}$ at $15^{\circ} \mathrm{C}$. $\Delta 12$-Desaturase specific activities were determined after incubation of membrane homogenates in the presence of $\left[1-{ }^{14} \mathrm{C}\right.$ ]oleoyl-CoA for $1 \mathrm{~h}$ at $30{ }^{\circ} \mathrm{C}$. [It should be stressed that this determination of desaturase activity underestimates total activity of the enzyme because of the desaturation of endogenous substrate, which occurs at approximately 10-12 times the rate found for exogenously added substrate (Jones et al., 1993a).] Mean values are shown from three replicate determinations \pm SEM where these exceed the dimensions of the symbols.

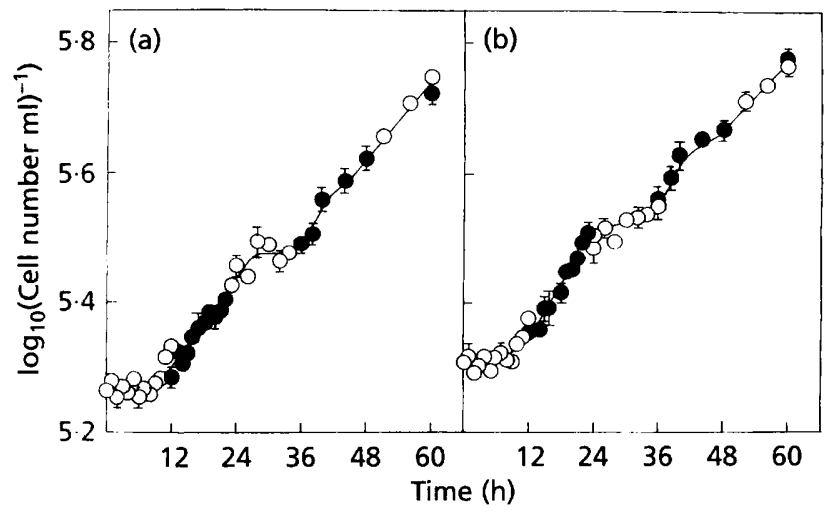

Fig. 3. Influence of chilling on cell division in 24 and $48 \mathrm{~h}$ cultures of $A$. castellanii. Cells grown at $30^{\circ} \mathrm{C}$ in $200 \mathrm{ml} \mathrm{PGY}$ medium for $24 \mathrm{~h}$ (a) and $48 \mathrm{~h}$ (b) were suspended to an approximate density of $2 \times 10^{5} \mathrm{ml}^{-1}$ in fresh medium at $15^{\circ} \mathrm{C}$. Cell numbers were determined at intervals over the subsequent $60 \mathrm{~h}$ incubation at $15^{\circ} \mathrm{C}$. Open (O) and filled (O) symbols represent results from independent experiments. Mean values are shown from counts of more than 1200 cells at each time point \pm SEM where these exceed the dimensions of the symbols.

ability of cells to resume cell division at the lower temperature. After resuspension of cells from $24 \mathrm{~h}$ (high degree of unsaturation) and $48 \mathrm{~h}$ (low degree of un- saturation) cultures in fresh medium at $15^{\circ} \mathrm{C}$, and incubation with shaking at $15^{\circ} \mathrm{C}$, a lag in cell division occurred in both cases (Fig. 3). No increase in cell numbers was evident in the initial $9.5 \mathrm{~h}$ of incubation at $15^{\circ} \mathrm{C}$, whereupon cells began to divide exponentially with doubling times of approximately $25 \mathrm{~h}$ and $21 \mathrm{~h}$ in cultures originally grown at $30^{\circ} \mathrm{C}$ for 24 and $48 \mathrm{~h}$, respectively. In both cases, a temporary cessation in cell division occurred approximately $24 \mathrm{~h}$ after incubation at $15^{\circ} \mathrm{C}$, at which stage cell numbers had increased by approximately $63 \%$ in both treatments. After approximately $36 \mathrm{~h}$, cell division resumed and a doubling in total cell numbers, from that present in the original inoculum at $15^{\circ} \mathrm{C}$, was evident after approximately $40 \mathrm{~h}$ incubation at $15{ }^{\circ} \mathrm{C}$ in both cases. The cell division times estimated from cell counts obtained between 48 and $60 \mathrm{~h}$ after chilling, were approximately 33.0 and $34.8 \mathrm{~h}$ in cultures originally grown at $30^{\circ} \mathrm{C}$ for 24 and $48 \mathrm{~h}$, respectively (Fig. 3). These values are similar to the cell doubling time of approximately $35 \mathrm{~h}$, estimated for continuous growth at $15^{\circ} \mathrm{C}$ (S. V. Avery, J. L. Harwood \& D. Lloyd, unpublished results).

Similar results to those described above were also obtained following chilling of 12,36 and $60 \mathrm{~h}$ cultures (results not shown). A longer initial lag in cell division, observed after chilling of $72 \mathrm{~h}$ cultures, was not related to lipid content but was probably a consequence of prolonged incubation in stationary phase at $30^{\circ} \mathrm{C}$ (Byers et al., 1991), as little difference in the fatty acid composition of 48,60 and $72 \mathrm{~h}$ cultures was evident.

\section{Influence of chilling on oxygen uptake and phagocytosis in $\mathbf{2 4}$ and $\mathbf{4 8} \mathrm{h}$ cultures of $A$. castellanii}

The effect of chilling on rates of oxygen uptake and phagocytosis was examined to see if any relationship could be detected between lipid unsaturation and physiological function in $A$. castellanii. The rate of oxygen uptake at $30{ }^{\circ} \mathrm{C}$ was approximately $55 \%$ higher in $24 \mathrm{~h}$ cultures, at approximately $18.0 \mathrm{nmol} \mathrm{O}_{2}\left(10^{6} \text { cells }\right)^{-1}$ $\min ^{-1}$, than in $48 \mathrm{~h}$ cultures (Fig. $4 \mathrm{a}$ ). Within $5 \mathrm{~min}$ of chilling cultures to $15^{\circ} \mathrm{C}$, rates of respiration (determined at $15{ }^{\circ} \mathrm{C}$ ) were reduced by approximately $73 \%$ and $64 \%$ in 24 and 48 h cultures, respectively. Respiration rates at $15^{\circ} \mathrm{C}$ were similar in both cases, and remained approximately constant between 4 and 5 nmol $\mathrm{O}_{2}\left(10^{6} \text { cells }\right)^{-1}$ $\min ^{-1}$, over the $12 \mathrm{~h}$ incubation period subsequent to chilling (Fig. 4a).

Rates of phagocytosis of $1 \mu \mathrm{m}$ latex beads were also determined both prior to, and at intervals for up to $12 \mathrm{~h}$ after chilling from $30^{\circ} \mathrm{C}$ to $15^{\circ} \mathrm{C}$ of 24 and $48 \mathrm{~h}$ cultures (Fig. 4b). In contrast to respiration, phagocytosis at $30^{\circ} \mathrm{C}$ was lower in $24 \mathrm{~h}$ cultures [at approximately $7 \cdot 3$ beads phagocytosed $(100 \text { cells })^{-1} \mathrm{~min}^{-1}$ than in $48 \mathrm{~h}$ cultures [approximately 17.5 beads $(100 \text { cells })^{-1} \mathrm{~min}^{-1}$ ]. However, only an approximate $44 \%$ reduction in phagocytosis was evident within $10 \mathrm{~min}$ of chilling $24 \mathrm{~h}$ cultures to $15^{\circ} \mathrm{C}$, whereas an approximate $98 \%$ decline, to approximately 0.4 beads $(100 \text { cells })^{-1} \mathrm{~min}^{-1}$, resulted at the lower temperature in $48 \mathrm{~h}$ cultures. In the $12 \mathrm{~h}$ period after chilling, 


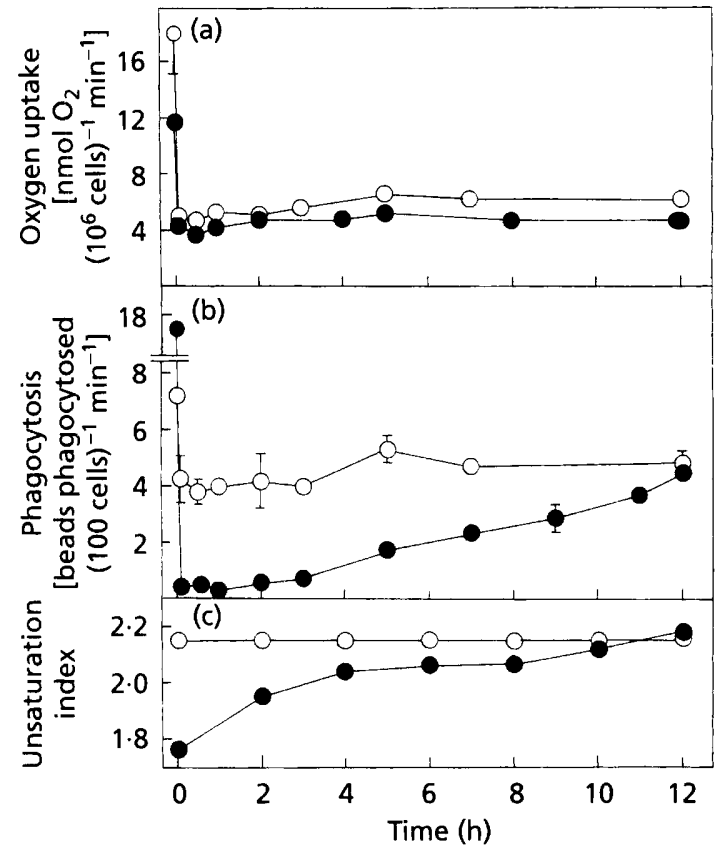

Fig. 4. Influence of chilling on respiration and phagocytosis in 24 and $48 \mathrm{~h}$ cultures of $A$. castellanii. Cultures were grown at $30^{\circ} \mathrm{C}$ in $200 \mathrm{ml} \mathrm{PGY} \mathrm{medium} \mathrm{for} 24 \mathrm{~h}(\mathrm{O})$ and $48 \mathrm{~h} \mathrm{(O)}$ and then chilled to $15^{\circ} \mathrm{C}$. Respiration (a), phagocytosis of latex beads (b) and the fatty acid unsaturation index (average number of double bonds per fatty acid) (c), were determined at intervals after incubation at $15^{\circ} \mathrm{C}$. Mean values from three replicate determinations are shown \pm SEM where these exceed the dimensions of the symbols.

rates of phagocytosis in the younger cultures increased slightly from approximately $4 \cdot 1$ to $4 \cdot 9$ beads $(100 \text { cells })^{-1}$ $\min ^{-1}$. In contrast, although the rate of phagocytosis remained relatively constant in the initial $3 \mathrm{~h}$ after chilling of $48 \mathrm{~h}$ cultures, an approximate 11 -fold increase was observed in the subsequent $9 \mathrm{~h}$ and the rate of phagocytosis $12 \mathrm{~h}$ after chilling was approximately 4.6 beads $(100 \text { cells })^{-1} \min ^{-1}$ (Fig. 4b).

The latter results were correlated with values for the fatty acid unsaturation index (mean number of double bonds per fatty acid) calculated at various intervals after chilling of 24 and 48 h cultures. Initially, the unsaturation index values for 24 and $48 \mathrm{~h}$ cultures at $30{ }^{\circ} \mathrm{C}$ were approximately $2 \cdot 15$ and $1 \cdot 76$, respectively (Fig. 4c). However, while no discernible change in the unsaturation index of $24 \mathrm{~h}$ cultures was evident in the $12 \mathrm{~h}$ period after chilling, that of $48 \mathrm{~h}$ cultures increased to approximately 2.04 within $2 \mathrm{~h}$ and to approximately $2 \cdot 18$ after $12 \mathrm{~h}$ incubation at $15^{\circ} \mathrm{C}$. This latter value was similar to that of $24 \mathrm{~h}$ cultures both before and after chilling (Fig. 4c).

\section{DISCUSSION}

Increases in the degree of membrane lipid unsaturation following exposure of organisms to lowered temperature have been widely documented and it is generally considered that a resultant increase in membrane fluidity (or an approximate maintenance of fluidity if measured at the ambient temperature) enables the organism to adapt physiologically to low temperatures. The results presented in this study indicate that adaptations in lipid metabolism to decreased temperature in the poikilothermic protozoon Acanthamoeba castellanii are markedly dependent on growth phase. In agreement with previous studies which examined late-exponential/early stationaryphase (40 h) cultures (Jones et al., 1991, 1993a), a rapid increase in fatty acid unsaturation resulted when $36-72 \mathrm{~h}$ cultures at $30^{\circ} \mathrm{C}$ were chilled to $15^{\circ} \mathrm{C}$. The changes in the proportions of oleate and linoleate in these older cultures occurred more rapidly than described previously (Jones et al., 1991). This was probably because, by initially immersing flasks in an ice slurry, the lower temperature was attained in less than $5 \mathrm{~min}$ in the present study, whereas in previous studies it took $1 \mathrm{~h}$. Previous studies have shown that growth- (Avery et al., 1994) and temperature- (Jones et al., 1993b) induced changes in fatty acid composition are similar in whole-cell homogenates, plasma membrane, mitochondrial and microsomal membrane fractions of $A$. castellanii. Therefore, the present results cannot be accounted for by changes in lipid composition during membrane flux. The enhanced relative synthesis of unsaturated fatty acids at low temperature, measured as an increase in $\Delta 12$-desaturase activity and a greater incorporation of radioactivity from $\left[1-{ }^{14} \mathrm{C}\right]$ acetate into polyunsaturated fatty acids, was only evident in lateexponential- and stationary-phase cultures. In early-and mid-exponential-phase cultures, no induction of fatty acid desaturation was apparent and the high degree of fatty acid unsaturation already in place in these young cultures was maintained at an approximately constant level in the $12 \mathrm{~h}$ subsequent to chilling. The growth-dependent changes indicate that temperature cannot be the sole 'messenger' that controls desaturase activation/synthesis in $A$. castellanii. However, the present results do not exclude many of the proposed mechanisms of desaturase induction, e.g. changes in rates of transcription of the gene encoding for the $\Delta 12$-desaturase in response to decreased membrane fluidity (Vigh et al., 1993), or control of desaturase activity by dissolved oxygen concentration, particularly as this latter parameter is affected by both culture growth and temperature change (Arneborg et al., 1993; Avery et al., 1994). It should be noted, however, that in Escherichia coli temperature can affect the degree of fatty acid unsaturation in the absence of any incidental changes in dissolved oxygen or growth rate (Arneborg et al., 1993).

Several workers have noted a lag in cell division following dilution of micro-organisms into fresh medium at lower temperature (Nozawa \& Kasai, 1978; Ferrante et al., 1983; Drebot et al., 1987; Hudson, 1993), and in certain cases this has been attributed to changes in membrane properties. Using freeze-fracture electron microscopy Nozawa \& Kasai (1978) demonstrated that the time taken for membrane particles to return to their normal homogeneous distribution following chilling of Tetrabymena pyriformis to $15^{\circ} \mathrm{C}$, coincided with that for the resumption of cell division. An approximate $10 \mathrm{~h}$ lag in cell division 
following chilling of late-exponential/early-stationaryphase cultures of $A$. castellanii was also correlated with the time required for the completion of most of the temperature-dependent changes in fatty acid composition (Jones tit al., 1991). The growth-dependent differences in temperature-induced membrane lipid adaptations of $A$. castellanii reported here, provide a good system for determining whether physiological effects of chilling are directly related to changes in the degree of unsaturation of membrane lipids. If increases in fatty acid unsaturation genuinely do enable organisms to adapt physiologically and resume cell division at low temperature, then it follows that mid-exponential-phase cells of $A$. castellanii would be able to adapt more rapidly to a decrease in temperature (because of their higher unsaturated fatty acid content) and perhaps be more tolerant to chilling stress, than stationary-phase cells. However, in the present study, dilution of cells from $24 \mathrm{~h}$ (high degree of fatty acid unsaturation) and $48 \mathrm{~h}$ (low degree of fatty acid unsaturation) cultures into fresh medium at $15^{\circ} \mathrm{C}$ resulted in a lag in cell division of approximately $9.5 \mathrm{~h}$ in both cases. Furthermore, the subsequent pattern of cell division and final cell yield after $60 \mathrm{~h}$ in both cultures were very similar. Thus, in contrast to previous suggestions, the initial lag in cell division seen on chilling of $A$. castellanii is not related to fatty acid composition. In fact, any effect that lipid composition could have on the process is masked by other factors such as, for example, cold-shock changes in metabolism.

Interestingly, a further lag in cell division was evident approximately $14 \mathrm{~h}$ after the initial resumption of cell division at $15^{\circ} \mathrm{C}$, suggesting that some degree of cellcycle sunchrony may have been induced under the conditions described. Production of synchronous cultures of $A$. castellanii using cold shock has been described previously (Neff \& Neff, 1964). The proposed mechanism of synchrony involves the disorganization of cortical structures, which develop during the cell cycle and must be completed before cell division can take place, so that cells are essentially rejuvenated to the earliest stage of the cell cycle following temperature shock (Zeuthen, 1964). However, the second lag observed here occurred after a doubling of only approximately $63 \%$ of the cells present in the original inoculum, suggesting that either the complicated growth kinetics may not be solely attributable to synchronous cell division, or that approximately $37 \%$ of the cells initially present were much more susceptible to cold-shock than the remainder. It is interesting that this latter figure correlates with the $37-47 \%$ of cells estimated to be present in the $G_{1}$ phase of the A. castellanii cell cycle (Edwards \& Lloyd, 1980), as differential sensitivity to cold and/or freeze-thaw shock is known to occur at different stages of the cell cycle in $E$. coli (Hodgson et al., 1992) and Saccharomyces cerevisiae (Cottrell, 1981). These differences may be related to cell cycle-dependent changes in membrane fluidity (Cottrell, 1981). It is stressed, however, that estimates for the relative importance of different stages in the cell cycle of A. castellanii differ considerably according to the method of analysis employed (Stöhr et al., 1987; Byers et al., 1991).
It should also be emphasized that the second lag in cell division observed here occurred only $24 \mathrm{~h}$ after temperature shift-down, although the average cell doubling time of $A$. castellanii at $15^{\circ} \mathrm{C}$ is approximately $35 \mathrm{~h}$. Thus, it is also possible that temperature shock synchronizes cultures with respect to circadian (approximately $24 \mathrm{~h}$ ) rhythmicity, and that an output of the circadian clock of A. castellanii is gating of cell division. It is interesting that numerous studies have suggested a role of membrane fatty acid composition in controlling the periodicity and temperature compensation of circadian rhythms (Mattern et al., 1982; Coté \& Brody, 1987; Rikin et al., 1993).

As with cell division, no marked difference in the effect of chilling on oxygen uptake in 24 and $48 \mathrm{~h}$ cultures was observed, suggesting that respiratory activity in $A$. castellanii may also be independent of the degree of fatty acid unsaturation of membrane lipids. It is of interest to note that, in experiments with sycamore cell cultures, Bligny et al. (1985) found that the activity of respiratory enzymes was unaffected by large changes in fatty acid unsaturation. It may be that the equivalent proteins in $A$. castellanii are also similarly insensitive or, alternatively, that the inner mitochondrial membrane is sufficiently unsaturated to be unaffected by chilling to $15^{\circ} \mathrm{C}$. Indeed, it is well known that the inner mitochondrial membrane does have a high unsaturation index in many organisms (see White, 1973; Harwood, 1985).

In contrast to cell division and oxygen uptake, phagocytotic activity in $A$. castellanii appeared to be closely related to the degree of fatty acid unsaturation of membrane lipids in the present study. A comparatively dramatic decline in the rate of phagocytosis was observed immediately following chilling of late-exponential/earlystationary-phase cultures, and a gradual subsequent increase in the rate of phagocytosis, to a final level similar to that of chilled exponential-phase cultures, coincided with a gradual increase in the fatty acid unsaturation index; little change in phagocytotic activity was observed in the $12 \mathrm{~h}$ subsequent to chilling of $24 \mathrm{~h}$ cultures, where the unsaturation index remained constant. Phagocytosis by A. castellanii is initiated by binding of a particle to the cell surface (Allen \& Dawidowicz, 1990), although binding of latex beads in the presence of sodium azide in our experiments showed little dependence on the degree of lipid unsaturation (results not shown). It therefore seems feasible to assume that the present observations were related to those properties of the plasma membrane which control its capacity to expand rapidly and invaginate during phagocytosis. To date, no studies have demonstrated a direct correlation between plasma-membrane fluidity and phagocytotic activity, although Mattox \& Thompson (1980) proposed that a decrease in the ability of $T$. pyriformis to form food vacuoles in the presence of high $\mathrm{Ca}^{2+}$ was related to a decline in the fluidity of foodvacuole membranes. Although a high degree of fatty acid unsaturation was advantageous to $A$. castellanii for phagocytosis at $15^{\circ} \mathrm{C}$, this was apparently not the case at $30^{\circ} \mathrm{C}$ where the rate of phagocytosis was greater in cells grown for $48 \mathrm{~h}$. One possibility is that the lower rate of phagocytosis in exponential phase cultures at $30^{\circ} \mathrm{C}$ was 
related to a higher degree of plasma-membrane fluidity / disorder and to some degree of membrane instability in these cells. The activities of several membrane-bound enzymes and transport systems at high temperature has been observed to decline with increasing membrane fluidity (Keenan et al., 1982; Hazel \& Williams, 1990).

Thus both growth- and temperature-dependent changes in fatty acid unsaturation appear to exert control over the rate of phagocytosis of $A$. castellanii. It has also been suggested that phagocytotic activity can itself affect the membrane phospholipid composition and several characteristic growth-dependent metabolic changes in $A$. castellanii. For example, Edwards \& Doulah (1982) demonstrated that enhanced production of AMP by $A$. castellanii after inoculation into fresh medium was related to phagocytosis of particles in the medium, as no such increase was observed following inoculation of cells into filtered or conditioned medium. Furthermore, a stimulation of oxygen uptake into cells occurs during phagocytosis by A. castellanii (Edwards \& Doulah, 1982; Davies et al., 1991). A clear relationship between phagocytotic activity and lipid metabolism by $A$. castellanii has been revealed by Allen \& Dawidowicz (1990), who demonstrated that phagocytosis caused rapid changes in the levels of certain cellular lipids, particularly phosphatidylinositol. In the light of their observations, a role of phagocytotic activity in the control of inositol-mediated intracellular signalling pathways of $A$. castellanii was proposed by these workers.

Clearly, a relationship is evident between the rate of phagocytosis and the extent of fatty acid unsaturation of A. castellanii. In addition to controlling the ingestion of food particles at different temperatures, data from others (discussed above) indicate that phagocytotic activity may also be concerned with a potential cascade of events which leads to further alterations in the metabolic and/or physiological status of the cell. Further studies are required to investigate such possible relationships in $A$. castellanii.

\section{ACKNOWLEDGEMENT}

The financial support of the Natural Environment Research Council (GR 3/8456) is gratefully acknowledged.

\section{REFERENCES}

Allen, P. G. \& Dawidowicz, E. A. (1990). Phagocytosis in Acanthamoeba. II. Soluble and insoluble mannose-rich ligands stimulate phosphoinositide metabolism. J Cell Pbysiol 145, 514-521.

Arneborg, N., Salskov-lversen, A. S. \& Mathiasen, T. E. (1993). The effect of growth rate and other growth conditions on the lipid composition of Escherichia coli. Appl Microbiol Biotechnol 39, 353-357.

Avery, S. V., Lloyd, D. \& Harwood, J. L. (1994). Changes in membrane fatty acid composition and $\Delta 12$-desaturase activity during growth of Acanthamoeba castellanii in batch culture. $J$ Eukaryot Microbiol 41, 384-389.

Bligh, E. G. \& Dyer, W. J. (1959). A rapid method of total lipid extraction and purification. Can J Biocbem Pbysiol 37, 911-917.

Bligny, R., Rebeillé, F. \& Douce, R. (1985). $\mathrm{O}_{2}$-triggered changes of membrane fatty acid composition have no effect on Arrhenius discontinuities of respiration in sycamore (Acer pseudoplantus I.) cells. J Biol Chem 260, 9166-9170.

Byers, T. J., Kim, B. G., King, L. E. \& Hugo, E. R. (1991). Molecular aspects of the cell cycle and encystment of Acanthamoeba castellanii. Rev Infect Dis 13, S373-S384.

Carroll, N. K. (1961). Separation of lipid classes by chromatography on florisil. J Lipid Res 2, 135-141.

Coté, G. G. \& Brody, S. (1987). Circadian rhythms in Neurospora crassa: membrane composition of a mutant defective in temperature compensation. Biocbim Biopbys Acta 898, 23-36.

Cottrell, S. F. (1981). Yeast freeze-thaw survival rates as a function of different stages of the cell cycle. Cryobiology 18, 506-510.

Davies, B., Chattings, L. S. \& Edwards, S. W. (1991). Superoxide generation during phagocytosis by Acanthamoeba castellanii: similarities to the respiratory burst of immune phagocytes. $J$ Gen Microbiol 137, 705-710.

Drebot, M. A., Johnston, G. C. \& Singer, R. A. (1987). A yeast mutant conditionally defective only for reentry into the mitotic cell cycle from stationary phase. Proc Natl Acad Sci US A 84, 7948-7952.

Edwards, S. W. \& Doulah, F. A. (1982). Elevation of AMP levels during phagocytosis in Acanthamoeba castellanii. J Gen Microbiol 128, 2919-2925.

Edwards, S. W. \& Lloyd, D. (1980). Oscillations in protein and RNA content during synchronous growth of Acanthamoeha castellanii-evidence for periodic turnover of macromolecules during the cell cycle. FEBS Lett 109, 21-26.

Ferrante, G., Ohno, Y. \& Kates, M. (1983). Influence of temperature and growth phase on desaturase activity of the mesophilic yeast Candida lipolytica. Can J Biochem Cell Biol 61, 171-177.

Golterman, H. L. (1969). Methods for Chemical Analysis of Fresh Waters. Oxford: Blackwell Scientific Publications.

Griffiths, G. \& Harwood, J. L. (1991). The regulation of triacylglycerol biosynthesis in cocoa (Theobroma cacao L.) Planta 184, 279-284.

Harwood, J. L. (1985). Plant mitochondrial lipids: structure, function and biosynthesis. In Higher Plant Cell Respiration, pp. 37-71. Edited by R. Douce \& D. A. Day. Berlin: Springer-Verlag.

Hazel, J. R. \& Williams, E. E. (1990). The role of alterations in membrane lipid composition in enabling physiological adaptation of organisms to their physical environment. Prog Lipid Res 29 , 167-227.

Hodgson, A., Evans, D. J., Brown, M. R. W. \& Gilbert, P. (1992). Involvement of cellular division cycle in the susceptibility of Escherichia coli to cold- and osmotic-shock. Microbios 72, 175-182.

Hudson, J. A. (1993). Effect of pre-incubation temperature on the lag time of Aeromonas bydrophila. Lett Appl Microbiol 16, 274-276.

Jones, A. L., Pruitt, N. L., Lloyd, D. \& Harwood, J. L. (1991). Temperature-induced changes in the synthesis of unsaturated fatty acids by Acanthamoeba castellanii. J Protozool 38, 532-536.

Jones, A. L., Lloyd, D. \& Harwood, J. L. (1993a). Rapid induction of microsomal $\Delta 12(\omega 6)$-desaturase activity in chilled Acanthamoeba castellanii. Biochem J 296, 183-188.

Jones, A. L., Hann, A. C., Harwood, J. L. \& Lloyd, D. (1993b). Temperature-induced membrane-lipid adaptation in Acanthamoeha castellanii. Biocbem J 290, 273-278.

Keenan, M. H. J., Rose, A. H. \& Silverman, B. W. (1982). Effect of plasma-membrane phospholipid unsaturation on solute transport into Saccharomyces cerevisiae NCYC 360. I Gen Microbiol 128, $2547-2556$.

Lloyd, D. \& Edwards, S. W. (1987). Temperature-compensated 
ultrad an rhythms in lower eukaryotes: timers for cell cycles and circad an events? In Advances in Cbronobiology, Part A, pp. 131-152. Edited by J. E. Pauly \& L. E. Scheving. New York: Alan R. Liss.

Lloyd, D., Edwards, S.W. \& Fry, J. C. (1982). Temperaturecompensated oscillations in respiration and cellular protein content in synchronous cultures of Acanthamoeba castellanii. Proc Natl Acad Sci $[S$ 1 79, 3785-3788.

Mattern, D. L., Forman, L. R. \& Brody, S. (1982). Circadian rhythms in Nestrospora crassa: a mutation affecting temperature compensation. Proc Natl Acad Sci US A 79, 825-829.

Mattox, S. M. \& Thompson, G. A., Jr (1980). The effects of high concentrations of sodium or calcium ions on the lipid composition and properties of Tetrabymena membranes. Biocbim Biopbys. Acta 599, 24-31.

Neff, R. J. \& Neff, R. H. (1964). Induction of synchronous division in amoebae. In Synchrony in Cell Division and Growth, pp. 213-246. Edited by E. Zeuthen. New York: Wiley Interscience.

Nozawa, Y. \& Kasai, R. (1978). Mechanism of thermal adaptation of membrane lipids in Tetrabymena pyriformis NT-1: possible evidence for temperature-mediated induction of palmitoyl-CoA desaturase. Biochim Biophys Acta 529, 54-66.

Rikin, A., Dillwith, J. W. \& Bergman, D. K. (1993). Correlation between the circadian rhythm of resistance to extreme temperatures and changes in fatty acid composition in cotton seedlings. Plant Pbysiol 101, 31-36.

Steinkamp, J. A., Wilson, J. S., Saunders, G. C. \& Stewart, C. C. (1982). Phagocytosis: flow cytometric quantitation with fluorescent microspheres. Science 215, 64-66.

Stöhr, M., Bommert, K., Schulze, I. \& Jantzen, H. (1987). The cell cycle and its relationship to development in Acanthamoeba castellanii. J Cell Sci 88, 579-589.

Vigh, L., Los, D. A., Horvath, I. \& Murata, N. (1993). The primary signal in the biological perception of temperature: Pd-catalyzed hydrogenation of membrane lipids stimulated the expression of the des A gene in Synechocystis PCC 6803. Proc Natl Acad Sci US A 90, 9090-9094.

White, D. A. (1973). The phospholipid composition of mammalian tissues. In Form and Function of Phospholipids, pp. 441-482. Edited by G. B. Ansell, J. N. Hawthorne \& R. M. C. Dawson. Amsterdam: Elsevier.

Zeuthen, E. (1964). The temperature-induced division synch rony in Tetrabymena. In Synchrony in Cell Division and Growth, pp. 99 158. Edited by E. Zeuthen. New York: Wiley Interscience.

Received 31 December 1993; revised 10 March 1994; accepted 28 March 1994. 